\title{
Sex-specific seasonal variation in the carotenoid content of sea urchin gonads
}

\author{
Nils T. Hagen*, Ida Jørgensen, Einar Skarstad Egeland \\ Faculty of Biosciences and Aquaculture, Bodø University College, 8049 Bodø, Norway
}

\begin{abstract}
This study documents the effect of sex on gonad carotenoid content during the annual reproductive cycle of Strongylocentrotus droebachiensis from northern Norway. Male and female S. droebachiensis exhibited distinctly different patterns of carotenoid variation, with seasonal carotenoid depletion and replenishment in females and carotenoid retention in males. Females lost approximately $71.1 \%$ of their echinenone during spawning, and compensated for the loss by active deposition during gonad regrowth. Female carotenoid levels (100 to $275 \mu^{-1} g^{-1}$ dry mass), although lower and less variable than male carotenoid levels, were consistently higher than predicted by estimates based on a constant post-spawning carotenoid content. Males did not lose carotenoids during spawning, and the concentration of carotenoids in male gonads varied from $>600$ to $<200 \mu \mathrm{g} \mathrm{g}^{-1}$ dry mass, apparently as a passive result of increasing gonad size. The results suggest that carotenoid supplements in urchin diets would be largely wasted in gonad enhancement cultivation of male $S$. droebachiensis, and emphasize the importance of controlling future feeding trials for the confounding effect of sex on carotenoid deposition.
\end{abstract}

KEY WORDS: Echinoid · Strongylocentrotus droebachiensis · Sex · Carotenoids · Seasonal variation · Gonad $\cdot$ Colour $\cdot$ Pigment

\section{INTRODUCTION}

Echinenone, the primary carotenoid in the gonads of edible sea urchins (Matsuno \& Tsushima 2001), is preferentially incorporated into the eggs of the green sea urchin Strongylocentrotus droebachiensis (Griffiths \& Perrott 1976). Female sea urchins, therefore, need to replenish their echinenone content on an annual basis (Lawrence et al. 2004). Sperm, however, does not contain carotenoids, and male sea urchins consequently may not require annual carotenoid replenishment. Since there are no known sex-related differences in the diet of sea urchins (Lawrence 1975, Lawrence et al. 2007), the implication is that sex-specific differences in carotenoid uptake, utilization, or deposition must exist.

The main purpose of the present study was to investigate sex-specific patterns of seasonal variation in the amount and concentration of carotenoid in sea urchin gonads by first testing, and rejecting, the null hypothesis of no sex-specific seasonal differences in the carotenoids of the gonads of Strongylocentrotus droe- bachiensis. The alternative hypothesis of carotenoid retention in males, and carotenoid depletion during spawning in females, is retained, and the pattern of sex-specific seasonal variation in gonadal carotenoid content and concentration is documented at monthly intervals for a full year. As S. droebachiensis is the primary candidate species for echiniculture in the North Atlantic region (Hagen 1996a, Pearce et al. 2004), the results of this study may prove useful by suggesting the advantage of sex-specific strategies for providing carotenoid supplements in urchin diets and pointing to the importance of controlling future feeding trials for the confounding effect of sex on carotenoid deposition.

\section{MATERIALS AND METHODS}

Sampling. Samples of Strongylocentrotus droebachiensis were collected at monthly intervals, between July 2005 and June 2006, at 2 nearby sites in the Mørkvedbukta, a small exposed bay next to the 
Marine Research Station of Bodø University College. Both sites are located in a partly overgrazed area intermingled by scattered patches of intact kelp vegetation, and were chosen to cover any microspatial environmental effects associated with wave exposure. One site is sheltered behind the tip of the harbour pier, while the other, at the headland opposite the pier, is fully exposed to wave action. Both sites were sampled by SCUBA diving at $<10 \mathrm{~m}$ depth. Collected urchins were dissected, and sexed by checking for oozing of ripe gametes, or, when necessary, by examination of gonad smears in a compound light microscope. Each monthly sample consisted of the first 5 females and the first 5 males from each site, for a total of 120 females and 120 males in the entire study.

Prior to dissection, routine measurements of body wet mass, test diameter and test height were recorded using laboratory scales with an accuracy of $0.01 \mathrm{~g}$ and electronic callipers with an accuracy of $0.01 \mathrm{~mm}$. Following dissection gonad wet mass was measured.

Relative gonad size was expressed as a gonad index (GI). To reduce allometric effects and better meet the GI's underlying assumption of an isometric relationship between gonad size and urchin size (Gonor 1972, Ebert 1999), the size range of urchins was restricted to 35 to $70 \mathrm{~mm}$ in test diameter. To maintain consistency with earlier studies, the GI was calculated as: GI = $100 \times$ gonad wet mass (g) / body wet mass (g) (Himmelman 1978, Falk-Pettersen \& Lønning 1983, Munk 1992, Hagen 1998, Meidel \& Scheibling 1998, Oganesyan 1998).

To remove the effect of seasonal changes in gonad water content (Fig. 1), relative gonad size was also expressed as gonad dry mass index: $\mathrm{GI}_{\mathrm{dry}}=100 \times$ gonad dry mass $(\mathrm{g}) /$ body wet mass $(\mathrm{g})$.

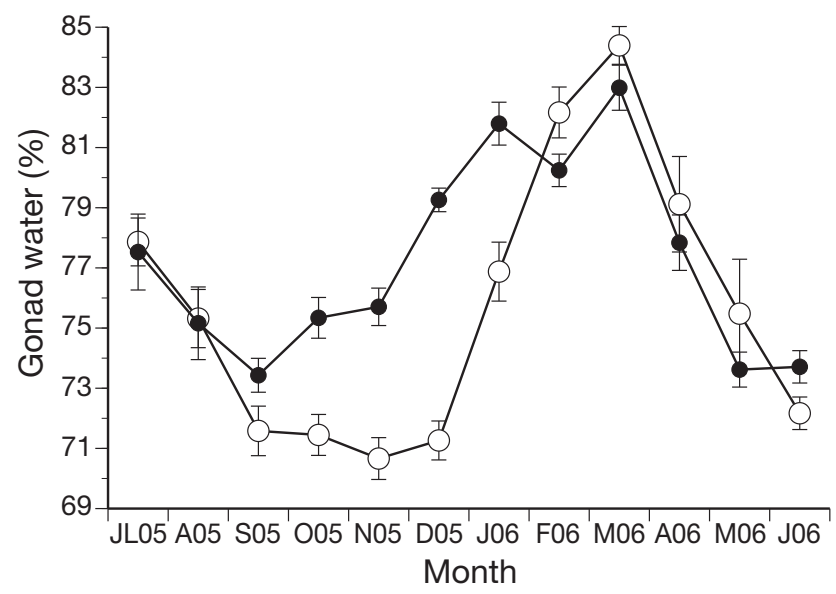

Fig. 1. Strongylocentrotus droebachiensis. Seasonal changes in mean percent gonad water content of female (O) and male (๑) urchins. $\mathrm{N}=10$ females and 10 males in each sample. Error bars: \pm SE
Carotenoid extraction and HPLC analysis. Gonad samples were frozen and kept at $-40^{\circ} \mathrm{C}$ for 3 to $4 \mathrm{~d}$ prior to freeze drying for at least $24 \mathrm{~h}$ in a Hetosicc CD 2,5 freeze dryer. Dried samples were stored at $3^{\circ} \mathrm{C}$ prior to carotenoid extraction. Samples of homogenized freeze-dried gonad tissue $(0.05 \mathrm{~g})$ were extracted repeatedly in $1 \mathrm{ml}$ of acetone. The extracts were evaporated to dryness using a TurboVap LV evaporator. The residue was then reconstituted in $0.5 \mathrm{ml}$ of acetone, filtered through a $0.2 \mu \mathrm{m}$ filter, transferred to a HPLC vial, flushed with $\mathrm{N}_{2}$ and sealed.

The HPLC analyses were performed on a Agilent 1100 instrument with a quaternary pump, thermostatted autosampler, thermostatted column compartment and a diode array UV-visible detector. The column was a reverse-phase Spheri 5 RP-18 $5 \mu \mathrm{m}$ column with precolumn (Brownlee Labs 0711-0017 from Perkin Elmer). A gradient system was used as eluant (0 min, 1:4 $1 \mathrm{M}$ ammonium acetate [aq]:methanol; $30 \mathrm{~min}, 7: 3$ methanol:acetone; $50 \mathrm{~min}, 3: 5: 2$ methanol:acetone:

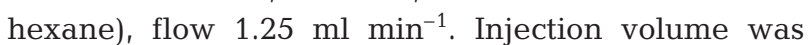
$20 \mu$ l. All analyses were performed with a column temperature of $25^{\circ} \mathrm{C}$ and detection wavelengths of 420 , 450 and $480 \mathrm{~nm}$ (HPLC System 4 in Egeland et al. 1995). The retention times were calibrated against standard reference samples of $\beta, \beta$-carotene and echinenone, kindly provided by Prof. Synnøve LiaaenJensen, NTNU, Trondheim.

Statistical analyses. The seasonal effect of sex on carotenoid content and concentration ( $\mu$ g carotenoids per $g$ gonad dry mass) was analysed in a series of independent comparisons for each monthly sample. Note that the term 'carotenoid content' refers to amount per urchin specimen, either expressed as $\mu \mathrm{g}$ carotenoids per $\mathrm{g}$ urchin wet mass (see Fig. 9), standardized to a fixed specimen size of $100 \mathrm{~g}$ wet mass (see Fig. 2), or illustrated as a function of carotenoid concentration and gonad size (see Figs. 5 to 7 ).

Prior to analysis, data were checked for normality and heteroscedasticity. Non-normality was alleviated by the Box-Cox transformation (Zar 1999), but heteroscedasticity in the concentration of total carotenoids and echinenone was not alleviated (Bartlett's test, p < 0.05). The effect of sex on these variables was therefore analysed using Welch's approximate $t$-test assuming unequal variances (Sokal \& Rohlf 1995). The residual variances were homogenous (Bartlett's test, $p>0.1$ ) for the total carotenoid content per specimen and for the concentration of $\beta, \beta$-carotene, which allowed a comparison between the ordinary $t$-test and Welch's approximate $t$-test. P-values for the 2 tests were identical to the third decimal place in all monthly comparisons.

Percentage data were analysed using non-parametric methods, i.e. Wilcoxon's rank-sum test, because 
parametric methods were rendered unsuitable by persistent non-normality and heteroscedasticity that could not be alleviated by data transformation (Sokal \& Rohlf 1995). All tests were supplemented by graphical analyses (Cleveland 1985).

The alternative hypothesis of carotenoid retention in males and carotenoid depletion during spawning in females was tested in a graphical analysis (Cleveland 1985), by contrasting dashed curves of best fit based on actual observations for all monthly samples, with solid curves depicting carotenoid concentration at different gonad sizes based on a constant carotenoid content matching the post-spawning sample from April (see Figs. 5 to 7). This graphical analysis was augmented by testing the prediction that if the curve of constant carotenoid content is an accurate representation of the data, then $50 \%$ of the observed values would be expected to lie on each side of the curve. The prediction was tested using a chi-squared test with 1 degree of freedom to compare the actual and predicted number of observations above and below the curve (Sokal \& Rohlf 1995).

Parameters for the von Bertalanffy growth curve (see Fig. 8) were obtained by adjusting parameters obtained from a study of tagged urchins held in the laboratory (Hagen 1996b), to reflect the larger asymptotic size $\left(D_{\infty}=65 \mathrm{~mm}\right)$, and reduced growth rate $(K=0.3)$, that befitted the sampled population. Age estimates were rounded to integer values.

\section{RESULTS}

\section{Rejecting the null hypothesis}

The total carotenoid content of male gonads was significantly higher than that of female gonads in 6 of the 12 monthly samples (Table 1), whereas the total carotenoid concentration of male gonads was more variable (Bartlett's test, $\mathrm{p}<0.05$ ), and significantly higher than that of female gonads in 7 of the 12 monthly samples (Table 1). These results are not consistent with the null hypothesis of no sex-specific seasonal differences in the carotenoids of the gonads of Strongylocentrotus droebachiensis. The null hypothesis was therefore rejected, and the alternatives explored.

\section{Sex-related seasonal variation in carotenoid content}

Female gonads had their lowest carotenoid content, and male gonads had their highest carotenoid concentration (Fig. 2) at the distinct post-spawning minimum in gonad size in April (Fig. 3). The post-spawning caro-
Table 1. Strongylocentrotus droebachiensis. Seasonal sexrelated differences in the content and concentration of gonad carotenoids. The total gonad carotenoid content per urchin specimen was standardized to an urchin size of $100 \mathrm{~g}$, and analysed using independent $t$-tests on Box-Cox transformed data. The total carotenoid concentration in the gonads was analysed using Welch's approximate $t$-test on Box-Cox transformed data. $\mathrm{N}=10$ females and 10 males in each sample. df: degrees of freedom; $t$ : $t$-value; ns: non-significant

\begin{tabular}{|lcrccccc|}
\hline $\begin{array}{l}\text { Sample } \\
\text { date }\end{array}$ & \multicolumn{3}{c}{ Total carotenoid } & \multicolumn{3}{c|}{ Total carotenoid } \\
& content & & \multicolumn{3}{c|}{ concentration } \\
& df & $t$ & $\mathrm{p}$ & $\mathrm{df}$ & $t$ & $\mathrm{p}$ \\
\hline Jul 2005 & 18 & 3.25611 & $<0.01$ & 17.32 & 3.55 & $<0.01$ \\
Aug 2005 & 18 & 1.60804 & $\mathrm{~ns}$ & 13.53 & 1.86 & $\mathrm{~ns}$ \\
Sep 2005 & 18 & 0.66141 & $\mathrm{~ns}$ & 14.50 & 1.67 & $\mathrm{~ns}$ \\
Oct 2005 & 18 & -0.40306 & $\mathrm{~ns}$ & 17.68 & -0.21 & $\mathrm{~ns}$ \\
Nov 2005 & 18 & 2.19358 & $<0.05$ & 15.89 & 2.37 & $<0.05$ \\
Dec 2005 & 18 & 1.85321 & $\mathrm{~ns}$ & 14.45 & 2.90 & $<0.05$ \\
Jan 2006 & 18 & 0.08544 & $\mathrm{~ns}$ & 17.40 & 1.76 & $\mathrm{~ns}$ \\
Feb 2006 & 18 & 2.66155 & $<0.05$ & 16.44 & 3.48 & $<0.01$ \\
Mar 2006 & 18 & -0.14259 & $\mathrm{~ns}$ & 17.95 & 1.44 & $\mathrm{~ns}$ \\
Apr 2006 & 18 & 3.08313 & $<0.01$ & 13.46 & 2.81 & $<0.05$ \\
May 2006 & 18 & 2.30813 & $<0.01$ & 18.00 & 2.83 & $<0.05$ \\
Jun 2006 & 18 & 3.93709 & $<0.01$ & 16.82 & 2.57 & $<0.05$ \\
& & & & & & \\
\hline
\end{tabular}
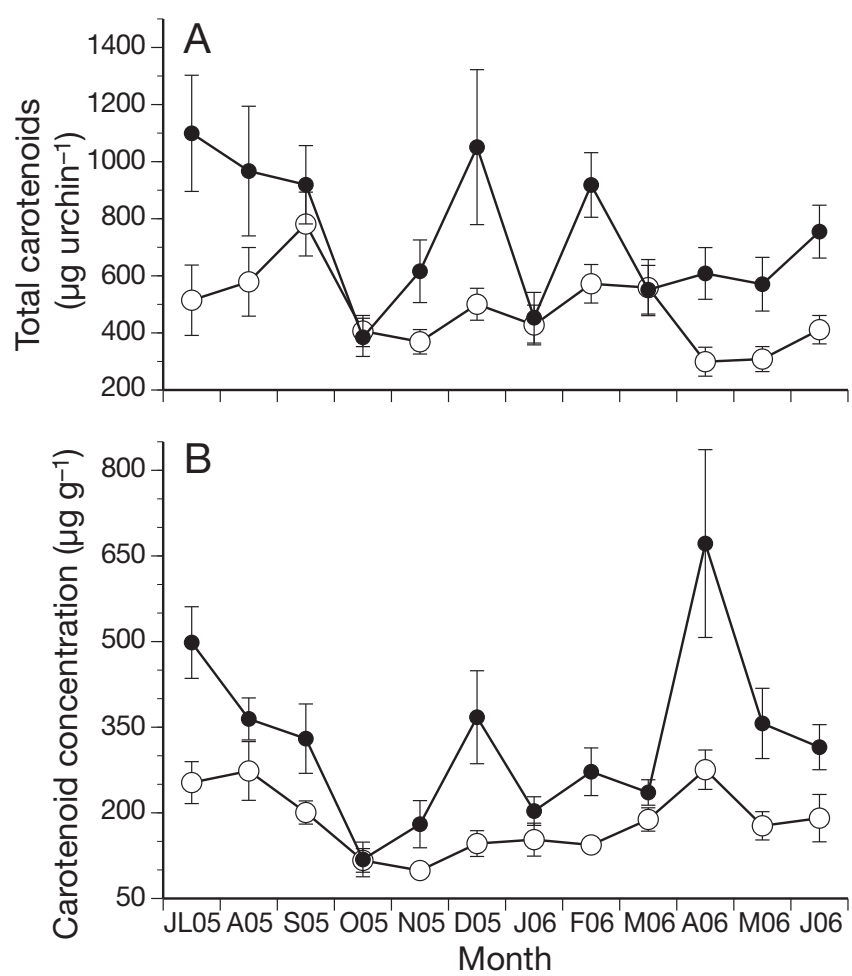

Fig. 2. Strongylocentrotus droebachiensis. Seasonal changes in the (A) content (total amount per specimen) and (B) concentration of carotenoids in the gonads of male $(\mathbf{)})$ and female $(O)$ urchins from Bodø, Norway, in monthly samples from July 2005 until June 2006. Total amounts are standardized for a specimen size of $100 \mathrm{~g}$ wet mass. $\mathrm{N}=10$ females and 10 males in each sample. Error bars: \pm SE 


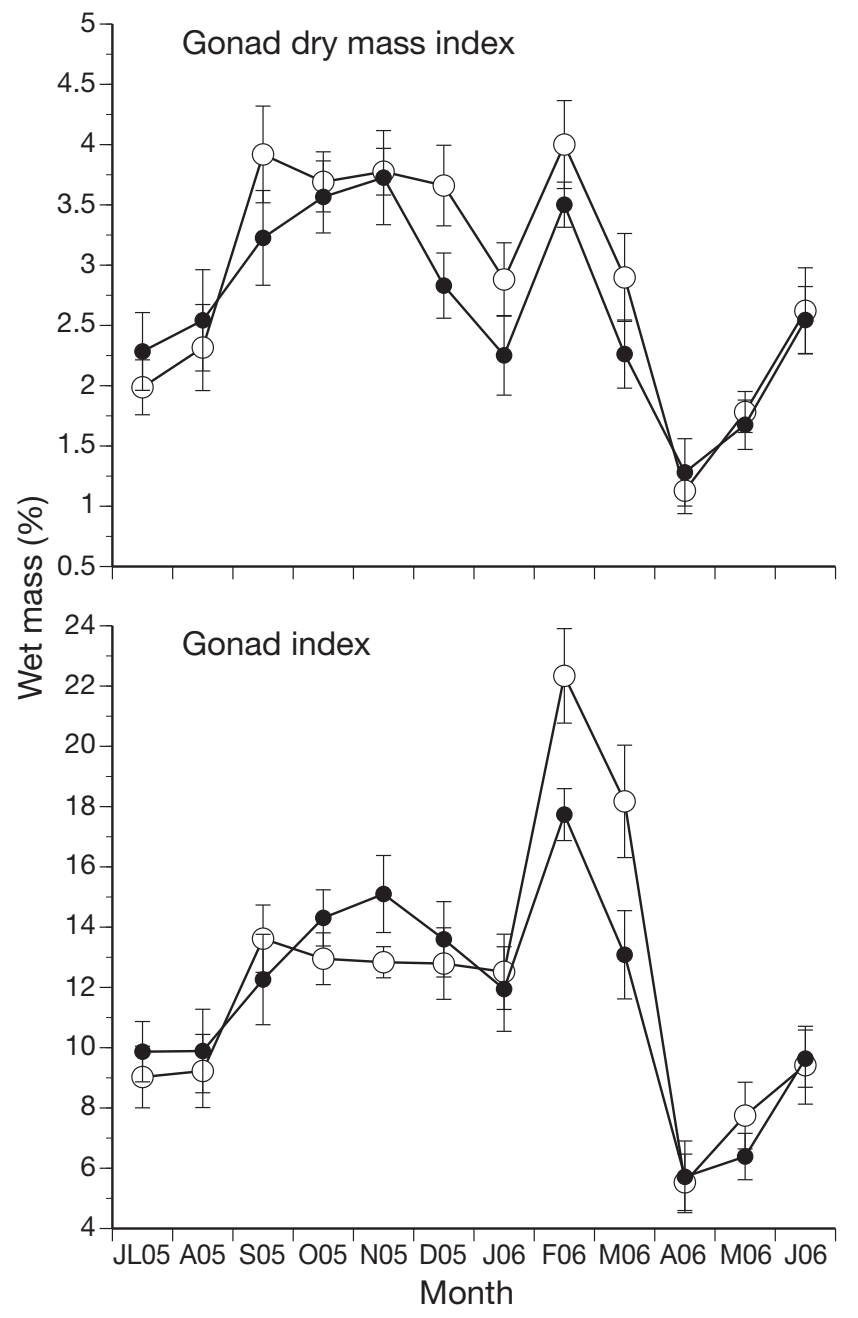

Fig. 3. Strongylocentrotus droebachiensis. Seasonal changes in the mean gonad dry mass index and the mean gonad index from July 2005 until June 2006. Females (O) and males (O) follow the same annual pattern, with a pre-spawning maximum in February and a post-spawning minimum in April. $\mathrm{N}=$ 10 females and 10 males in each sample. Error bars: \pm SE

tenoid content and concentration of male and female gonads differed significantly, but the difference between the sexes decreased to non-significance in $\mathrm{Au}$ gust (Table 1). However, the total carotenoid concentration for both sexes continued to decrease until October or November (Fig. 2), when gonad dry mass had fully recovered from spawning (Fig. 3).

These results are consistent with an alternative hypothesis of seasonal carotenoid depletion and replenishment in females, and carotenoid retention in males.

The seasonal pattern of decreasing carotenoid concentration differed between the sexes in that the total carotenoid concentration of male gonads declined steadily between April and October, while females maintained relatively high carotenoid levels until August and then declined (Fig. 2). These results suggest that carotenoid concentration of male gonads decreases as a passive function of increasing gonad size, while the carotenoid content of female gonads is being actively replenished as gonads grow.

Male echinenone levels fluctuated around $90 \%$ of total carotenoid content in all monthly samples (Fig. 4), but female levels, while similar to male levels in winter, were significantly lower in summer (Fig. 4, Table 2). The decrease in female echinenone levels occurred during the spawning season in March to April, and coincided with a significant increase in the level of
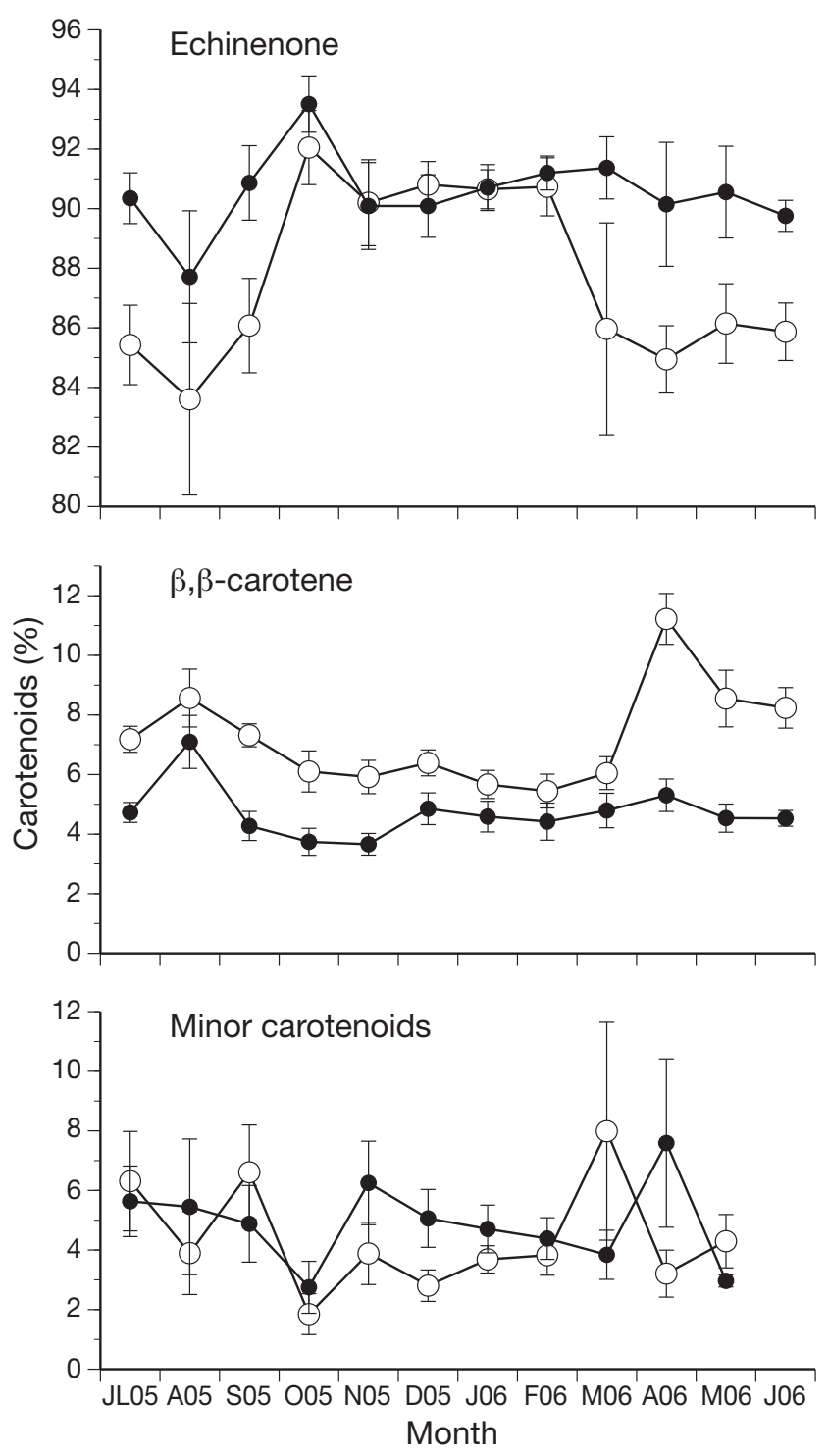

Fig. 4. Strongylocentrotus droebachiensis. Seasonal changes in the proportion of echinenone, $\beta, \beta$-carotene and minor carotenoids in the gonads of male $(\bullet)$ and female $(O)$ urchins. $\mathrm{N}=10$ females and 10 males in all samples, except where otherwise indicated in Table 2. Error bars: \pm SE 
Table 2. Strongylocentrotus droebachiensis. Seasonal sex-related differences in the percentage of major carotenoids in the gonads analysed using Wilcoxon's rank sum test. $\mathrm{N}=10$ females and 10 males in each sample, except where otherwise indicated in parentheses. $\mathrm{R}_{1}$ : sum of female rank scores; $\mathrm{R}_{2}$ : sum of male rank scores; ns: non-significant

\begin{tabular}{|c|c|c|c|c|c|c|c|c|c|}
\hline \multirow{2}{*}{$\begin{array}{l}\text { Sample } \\
\text { date }\end{array}$} & \multicolumn{3}{|c|}{ \% Echinenone } & \multicolumn{3}{|c|}{$\% \beta, \beta$-carotene } & \multicolumn{3}{|c|}{$\%$ Minor carotenoids } \\
\hline & $\mathrm{R}_{1}$ & $\mathrm{R}_{2}$ & $\mathrm{p}$ & $\mathrm{R}_{1}$ & $\mathrm{R}_{2}$ & $\mathrm{p}$ & $\mathrm{R}_{1}$ & $\mathrm{R}_{2}$ & $\mathrm{p}$ \\
\hline Jul 2005 & 68 & 142 & $<0.01$ & 147 & 63 & $<0.001$ & $28(5)$ & $27(5)$ & ns \\
\hline Aug 2005 & 90 & 120 & ns & 122 & 88 & $\mathrm{~ns}$ & 36 (5) & 54 (8) & ns \\
\hline Sep 2005 & 74 & 136 & $<0.05$ & 148 & 62 & $<0.01$ & 113 & 97 & ns \\
\hline Oct 2005 & 96 & 114 & $\mathrm{~ns}$ & 136 & 74 & $<0.05$ & 87 & 123 & ns \\
\hline Nov 2005 & 100 & 110 & $\mathrm{~ns}$ & 140 & 70 & $<0.01$ & 90 & 120 & ns \\
\hline Dec 2005 & 104 & 106 & $\mathrm{~ns}$ & 138 & 72 & $<0.01$ & 87 & 123 & ns \\
\hline Jan 2006 & 107 & 103 & $\mathrm{~ns}$ & 124 & 86 & $\mathrm{~ns}$ & 97 & 113 & ns \\
\hline Feb 2006 & 93 & 117 & $\mathrm{~ns}$ & 119 & 91 & $\mathrm{~ns}$ & 93 & 117 & ns \\
\hline Mar 2006 & 83 & 127 & $\mathrm{~ns}$ & 126 & 84 & $\mathrm{~ns}$ & 117 & 93 & ns \\
\hline Apr 2006 & 79 & 131 & $<0.05$ & 154 & 56 & $<0.001$ & $39(7)$ & 39 (5) & ns \\
\hline May 2006 & 77 & 133 & $<0.05$ & 145 & 65 & $<0.01$ & $23(5)$ & $5(2)$ & ns \\
\hline Jun 2006 & 71 & 139 & $<0.05$ & 149 & 61 & $<0.001$ & - & - & - \\
\hline
\end{tabular}

$\beta, \beta$-carotene (Fig. 4, Table 2). This result is an indication of preferential incorporation of echinenone in the eggs, and subsequent depletion during spawning.

The proportion of $\beta, \beta$-carotene in female gonads was higher than that in male gonads in 8 of the 12 monthly samples (Table 2, Fig. 4), but the actual concentration of $\beta, \beta$-carotene in male and female gonads was not significantly different in any of the samples (Welch's approximate $t$-test, $\mathrm{p}>0.05$ ), suggesting that the observed differences in the proportions of $\beta, \beta$-carotene were passive results of differences in echinenone concentration.

Minor carotenoids of both sexes fluctuated between 2 and $8 \%$ of total carotenoid content, with no expressed seasonal pattern (Fig. 4) and no significant differences between males and females (Table 2).

\section{Reproductive cycle}

The observed seasonal changes in the gonad index of Strongylocentrotus droebachiensis reflect its annual reproductive cycle, with a pre-spawning maximum in February and a post-spawning minimum in April, followed by a steady increase until September or October, a pause in November or December, and then a final pre-spawning increase between January and February (Fig. 3). Females and males follow the same basic pattern, the only conspicuous difference being that females reach a significantly higher pre-spawning peak (Table 3).

When the gonad index is calculated using gonad dry mass instead of gonad wet mass, the overall annual pattern is retained in a simpler form, i.e. the prespawning peak and the minor sex-related differences disappear (Fig. 3, Table 3), indicating that they were caused by differences in gonad water content (Fig. 1). The dry mass of the gonads was fully restored approximately 5 mo after the post-spawning minimum.

The annual reproductive output of female urchins was estimated by comparing the pre-spawning average gonad dry mass index of $3.66 \%$ with the postspawning value of $1.13 \%$, which indicated that approximately $(100-1.13 \times$ $100 / 3.66)=69.1 \%$ of the gonad dry mass was lost during spawning.

\section{Assessing the alternative hypothesis}

The alternative hypothesis of seasonal carotenoid depletion and replenishment in females, and carotenoid retention in males was assessed by contrasting dashed curves of best fit, based on actual observations for all monthly samples, with solid curves depicting carotenoid concentration at different gonad sizes based on a constant carotenoid content matching the post-spawning sample from April (Figs. 5 to 7 ).

For females the dashed curves of best fit are located above the curves of constant total carotenoid content (Fig. 5) and constant echinenone content (Fig. 6). The actual values for total carotenoids and echinenone are consistently higher than predicted by the curves of constant carotenoid content (chi-squared test, $\mathrm{p}<0.05$ ), indicating replenishment of echinenone lost during spawning. The female curves for $\beta, \beta$-carotene coincide

Table 3. Strongylocentrotus droebachiensis. Seasonal sexrelated differences in relative gonad size analysed using Wilcoxon's rank sum test. $\mathrm{N}=10$ females and 10 males in each sample. $R_{1}$ : sum of female rank scores; $R_{2}$ : sum of male rank scores; ns: non-significant

\begin{tabular}{|lrrcrrr|}
\hline \multirow{2}{*}{ Sample date } & \multicolumn{3}{c}{ Gonad index } & \multicolumn{4}{c|}{ Gonad dry mass index } \\
& $\mathrm{R}_{1}$ & \multicolumn{1}{c}{$\mathrm{R}_{2}$} & $\mathrm{p}$ & $\mathrm{R}_{1}$ & $\mathrm{R}_{2}$ & $\mathrm{p}$ \\
\hline Jul 2005 & 100 & 110 & $\mathrm{~ns}$ & 96 & 114 & $\mathrm{~ns}$ \\
Aug 2005 & 106 & 104 & $\mathrm{~ns}$ & 102 & 108 & $\mathrm{~ns}$ \\
Sep 2005 & 112 & 98 & $\mathrm{~ns}$ & 115 & 95 & $\mathrm{~ns}$ \\
Oct 2005 & 93 & 117 & $\mathrm{~ns}$ & 108 & 102 & $\mathrm{~ns}$ \\
Nov 2005 & 87 & 123 & $\mathrm{~ns}$ & 104 & 106 & $\mathrm{~ns}$ \\
Dec 2005 & 102 & 108 & $\mathrm{~ns}$ & 129 & 81 & $\mathrm{~ns}$ \\
Jan 2006 & 108 & 102 & $\mathrm{~ns}$ & 123 & 87 & $\mathrm{~ns}$ \\
Feb 2006 & 133 & 77 & $<0.05$ & 115 & 95 & $\mathrm{~ns}$ \\
Mar 2006 & 131 & 79 & $<0.05$ & 121 & 89 & $\mathrm{~ns}$ \\
Apr 2006 & 105 & 105 & $\mathrm{~ns}$ & 103 & 107 & $\mathrm{~ns}$ \\
May 2006 & 123 & 87 & $\mathrm{~ns}$ & 114 & 96 & $\mathrm{~ns}$ \\
Jun 2006 & 103 & 107 & $\mathrm{~ns}$ & 105 & 105 & $\mathrm{~ns}$ \\
\hline
\end{tabular}




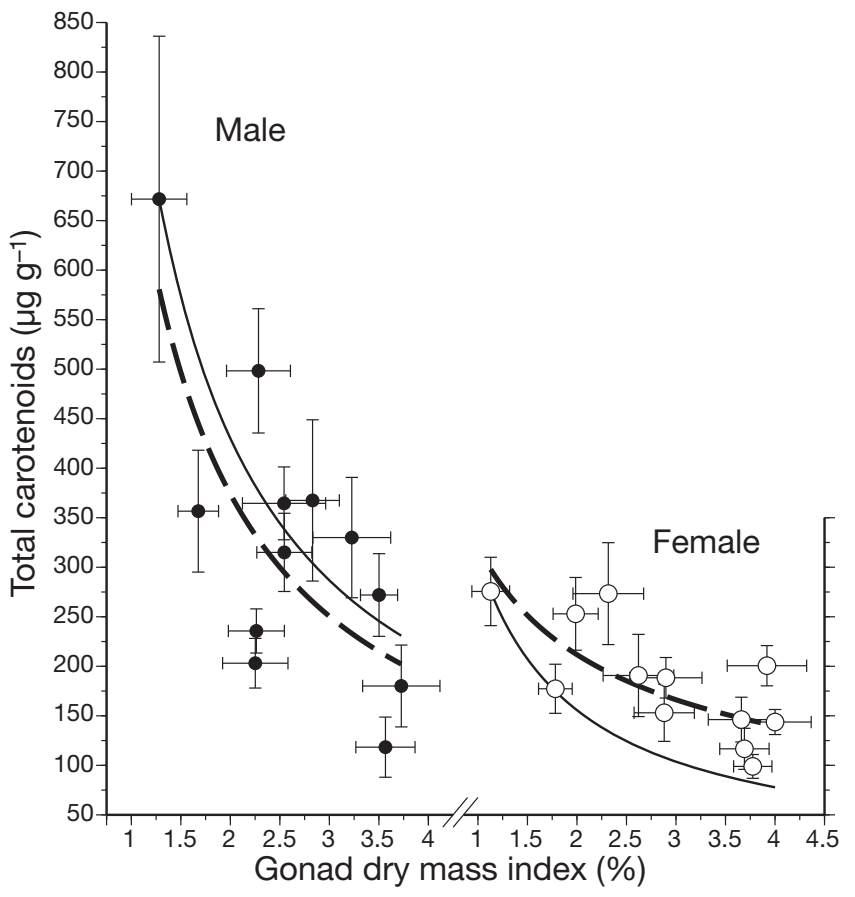

Fig. 5. Strongylocentrotus droebachiensis. Relationship between gonad size and total carotenoid concentration of male $(\bullet)$ and female $(O)$ urchins. The thin, unbroken curve depicts a constant carotenoid content based on the post-spawning sample from April 2006, and the thick, dashed curve represents the actual relationship between gonad dry mass index and carotenoid concentration. $\mathrm{N}=10$ females and 10 males in each sample. Error bars: $\pm \mathrm{SE}$

with observed values scattered around the curves (Fig. 7; chi-squared test, $p>0.05$ ), suggesting that variation is not a function of gonad size.

For males, the dashed curves of best fit are consistently below the solid curves of constant carotenoid content (Figs. 5 to 7), but the actual values are scattered around the curves of constant carotenoid content (chi-squared test, $\mathrm{p}>0.05$ ), suggesting that the overall carotenoid content in male gonads is seasonally stable.

This analysis is consistent with the alternative hypothesis, and, given that dietary carotenoid availability is likely to be identical for both sexes, suggests that carotenoid supersaturation is actively prevented in male Strongylocentrotus droebachiensis.

\section{DISCUSSION}

\section{Sex-related variation in carotenoid content}

\section{Seasonal}

Male and female Strongylocentrotus droebachiensis exhibit distinctly different annual cycles of gonad carotenoid content, with seasonal carotenoid depletion and

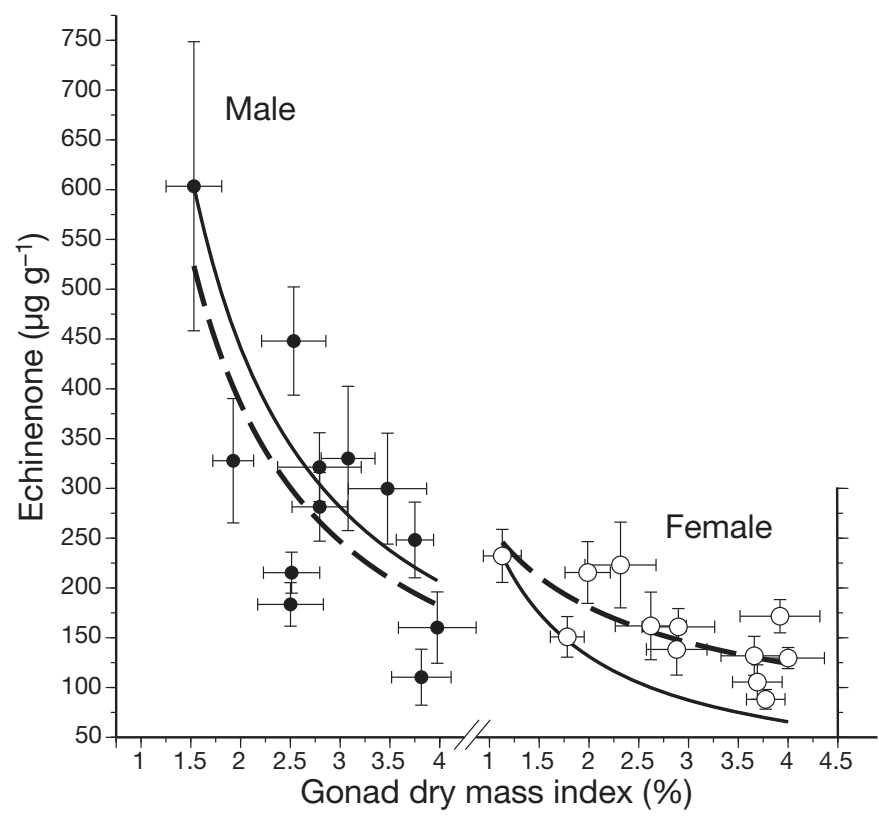

Fig. 6. Strongylocentrotus droebachiensis. Relationship between gonad size and echinenone concentration in the gonads of male ( ) and female (O) urchins. The thin, unbroken curve represents a constant content of echinenone based on the post-spawning sample from April 2006, and the thick, dashed curve depicts the actual relationship between gonad dry mass index and echinenone concentration. $\mathrm{N}=10$ females and 10 males in each sample. Error bars: \pm SE

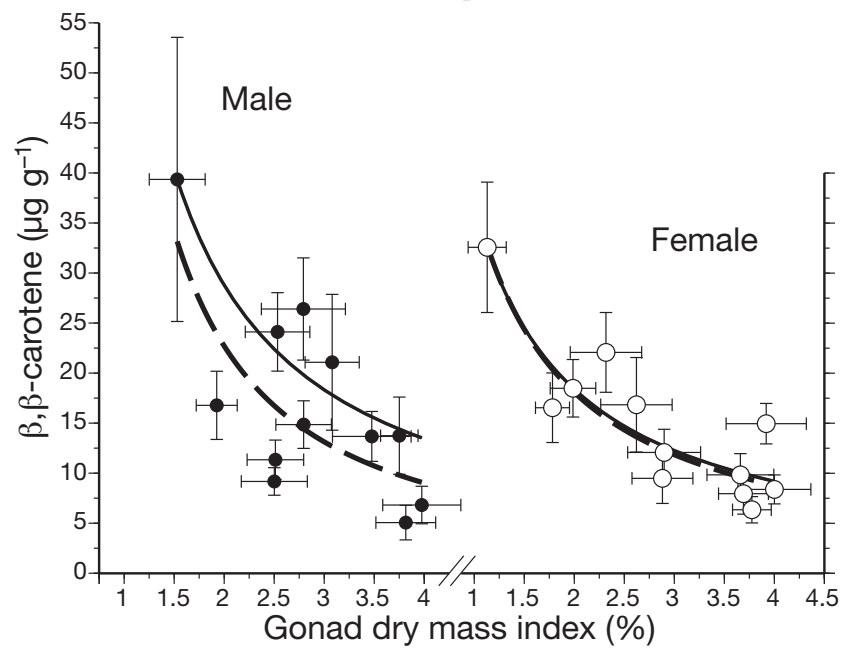

Fig. 7. Strongylocentrotus droebachiensis. Concentration of $\beta, \beta$ carotene in the gonads of male $(\bullet)$ and female $(O)$ urchins. The thin, unbroken curve represents a constant content of $\beta, \beta$-carotene based on the post-spawning sample from April 2006, and the thick, dashed curve depicts the actual relationship between gonad index and $\beta, \beta$-carotene concentration. $\mathrm{N}=10$ females and 10 males in each sample. Error bars: \pm SE

replenishment in females, and carotenoid retention in males. Females lose echinenone during spawning, and compensate the loss by active deposition during gonad regrowth. Males, however, do not lose carotenoids dur- 
ing spawning, since sperm does not contain carotenoids, nor is there evidence of post-spawning deposition. The post-spawning concentration of carotenoids in male gonads, therefore, appears to decrease as a passive result of increasing gonad size.

Echinenone levels in female gonads declined from a pre-spawning level of $90.7 \%$ to a post-spawning level of $84.9 \%$, coinciding with a reproductive output equivalent to $69.1 \%$ of the gonad dry mass. These figures provide an estimate of echinenone levels in the eggs of approximately $[(90.7 \times 100-(100-69.1) \times 84.9) / 69.1]=93.3 \%$, which suggests that echinenone is preferentially incorporated into eggs (cf. Griffiths \& Perrott 1976) and that the echinenone level in the eggs is approximately $(93.3$ $-84.9)=8.4 \%$ higher than in the residual gonad tissue. Lawrence et al. (2004) calculated carotenoid concentrations in terms of wet mass, and found that the level of echinenone in the eggs of Strongylocentrotus droebachiensis was $8.8 \%$ higher than in unspawned gonads.

The above figures also provide an estimate of an annual echinenone output equal to $(69.1 \times 93.3 / 90.7)$ $=71.1 \%$ of the total pre-spawning content in the female gonads. Alternatively, the total annual output of carotenoids can be estimated as the percent difference between pre- (February, $5.72 \mu \mathrm{g} \mathrm{g}^{-1}$ urchin wet mass) and post- (April, $2.99 \mu \mathrm{g} \mathrm{g}^{-1}$ urchin wet mass) spawning carotenoid content in female urchins [(5.72 2.99) $\times 100 / 5.72$ ] $=47.7 \%$ (cf. Fig. 2)

The average pre-spawning concentration of total carotenoids in female gonads was $147.7 \mathrm{\mu g} \mathrm{g}^{-1}$ dry mass, which gives an estimated echinenone concentration in the eggs equal to $(147.7 \times 93.3 / 100)=137.8 \mu \mathrm{g}$ $\mathrm{g}^{-1}$ dry mass, which is almost identical to a previous estimate by Griffiths \& Perrott (1976).

Contrary to the present results, and to the previously published results (Griffiths \& Perrott 1976, Lawrence et al. 2004), Lamare \& Hoffman (2004) found a reverse relationship in which the total carotenoid concentration in eggs of Strongylocentrotus droebachiensis was a mere $\sim 30 \mu \mathrm{g} \mathrm{g}^{-1}$ dry mass, although the total carotenoid concentration of the gonads was $\sim 260 \mu \mathrm{g} \mathrm{g}^{-1}$ dry mass. Lamare \& Hoffman's (2004) estimate of total carotenoid concentration in the eggs of $S$. droebachiensis is a mean value based on a sample of 5 females, yet their mean value is only a third of the minimum value of $88 \mathrm{\mu g} \mathrm{g}^{-1}$ (maximum: $247 \mu \mathrm{g} \mathrm{g}^{-1}$, mean: $137 \mu \mathrm{g} \mathrm{g}^{-1}$ ) dry mass found in an earlier sample of 15 females from the same area of the NE Pacific (Griffiths \& Perrott 1976). Clearly, resampling is required to resolve this discrepancy.

\section{Annual}

The present results suggest that the carotenoid content of male gonads would increase by an annual amount equivalent to the amount released by females during spawning, and that the pre-spawning carotenoid content of female gonads would remain approximately constant from one year to the next. To assess this scenario, all urchins in the sample were first divided into age groups according to a von Bertalanffy growth curve (Fig. 8). Then the predicted carotenoid content of male sea urchins (Fig. 9) was calculated to reflect an annual increase of $50 \%$, corresponding to an observed spawning related loss of $47.7 \%$ of the total carotenoids of female sea urchins.

Female urchins conformed well to a predicted pattern of seasonal variation without any age-related increase in carotenoid content (Fig. 9). In contrast, although the carotenoid content of male urchins initially appeared to increase as predicted, the predicted levels surpassed observed levels for urchins aged $>7 \mathrm{yr}$ (Fig. 9). This analysis suggests that the observed maximum total carotenoid level of approximately $25 \mu \mathrm{g} \mathrm{g}^{-1}$ urchin wet mass represents a supersaturation threshold.

Interestingly, males were significantly under-represented in the $\geq 10$ yr age group (chi-squared contingency analysis, $\mathrm{p}<0.05$ ). The possibility that extreme carotenoid levels may have a negative effect on male longevity can therefore not be repudiated.

\section{Implications for gonad enhancement cultivation}

High-quality sea urchin gonads have a uniform yellowish-orange colour that has proven difficult to attain in cultivation trials (Robinson et al. 2002). Gonad colour is a function of carotenoid content, and substandard colour is a direct result of carotenoid levels being

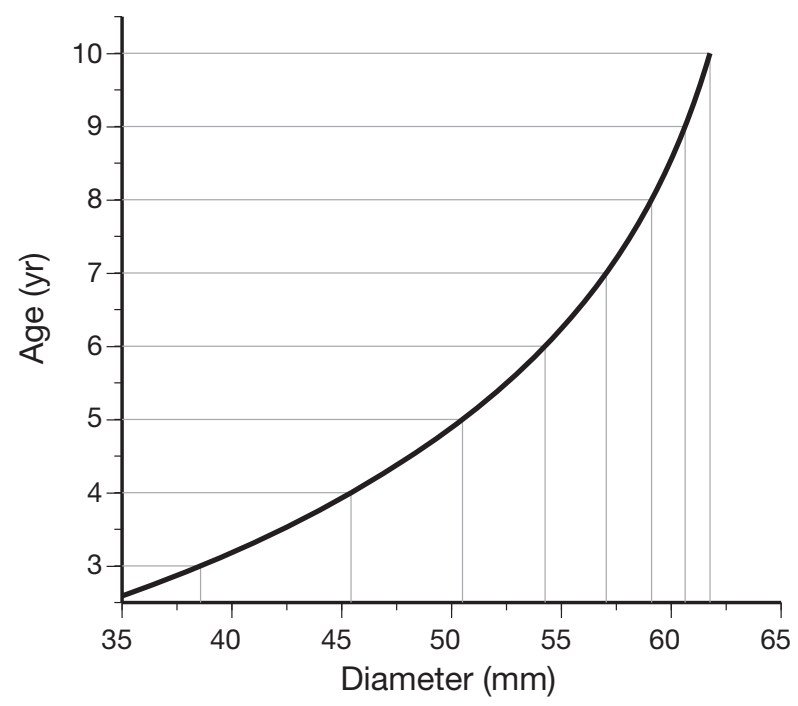

Fig. 8. Strongylocentrotus droebachiensis. The von Bertalanffy growth curve used to assign urchins to age groups 


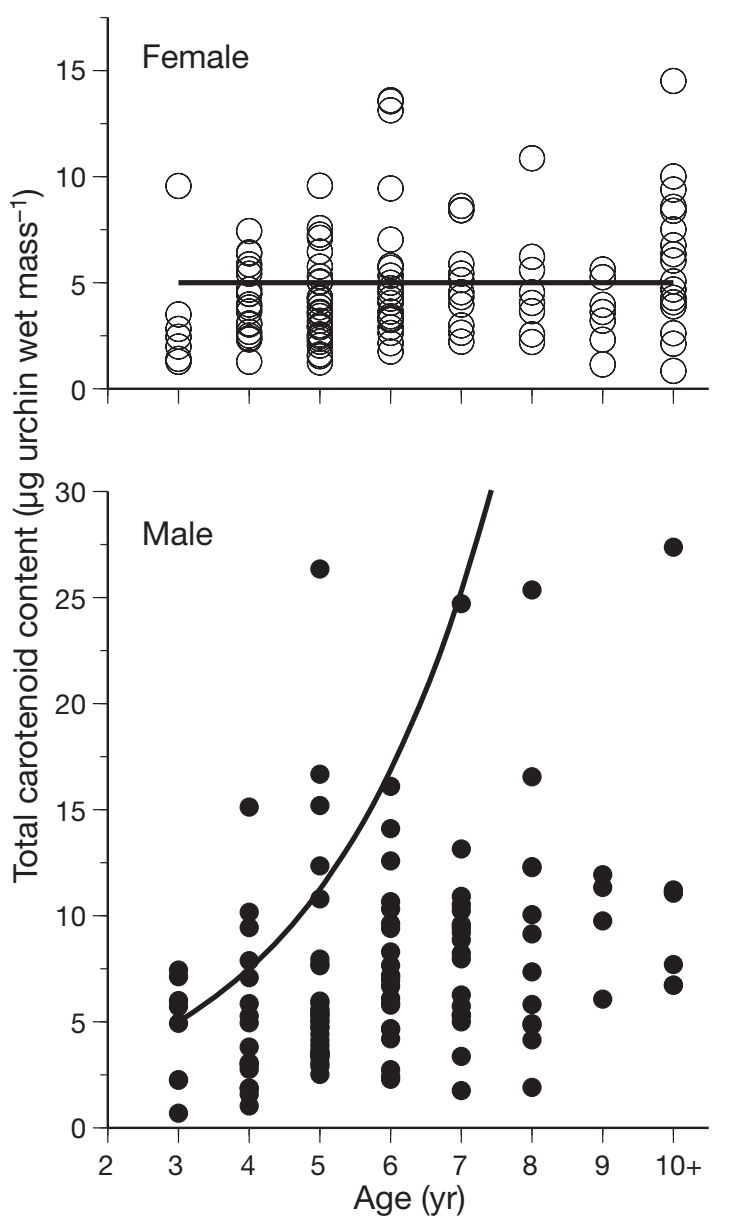

Fig. 9. Strongylocentrotus droebachiensis. Predicted and observed patterns of annual variation in the total carotenoid content of male $(\bullet)$ and female $(O)$ sea urchin gonads. Female gonads conformed well to a predicted pattern of seasonal variation without any age-related increase in carotenoid content. Male gonads have a larger content range and tend to contain more carotenoids than female gonads, but predicted values surpassed observed values for urchins aged $>7 \mathrm{yr}$

too high, leading to dark miscolouration, or too low, leading to unattractive paleness. The primary problem in gonad enhancement cultivation is paleness, which occurs when gonad growth is more rapid than carotenoid deposition (Plank et al. 2002). Sea urchins cannot synthesize carotenoids de novo, and paleness, although ostensibly due to an insufficient supply of dietary carotenoids (Pearce et al. 2003, Shpigel et al. 2006), is difficult to remedy, partly because deposition is complicated by the bioconversion of dietary $\beta, \beta$-carotene to echinenone (Tsushima 2007).

Echinenone deposition is limited by the availability, uptake and bioconversion of $\beta, \beta$-carotene from natural dietary sources (Tsushima 2007). As there are no known sex-related feeding preferences in sea urchins (Lawrence 1975, Lawrence et al. 2007), the present study suggests that males may reach a saturation threshold for echinenone at which either the uptake or bioconversion of $\beta, \beta$-carotene is curtailed. Alternatively, males may have evolved some unknown ability to dispose of excess echinenone. In either case, carotenoid supplements in urchin diets would be largely wasted in gonad enhancement cultivation of male Strongylocentrotus droebachiensis.

In conclusion, this analysis emphasizes the importance of controlling future feeding trials for the confounding effect of sex on carotenoid deposition, and suggests that gonad enhancement cultivation of sea urchins may benefit from sex-specific strategies for providing carotenoid supplements in urchin diets.

Acknowledgements. Thanks to H. H. Ludviksen and E. Tryggestad for competent technical assistance, and to H. K. Marshall for improving the logical flow and linguistic content of the manuscript. Bodø University College, Norway, generously provided technical assistance, laboratory facilities, and time for manuscript preparation. This study was supported by the SPIINES 2 project (COOP-CT-2004-512627), and special thanks are due to $\mathrm{M}$. Kelly for initiating and coordinating the project.

\section{LITERATURE CITED}

Cleveland WS (1985) The elements of graphing data. Wadsworth Advanced Books and Software, Monterey, CA

Ebert TA (1999) Plant and animal populations. Methods in demography. Academic Press, San Diego, CA

Egeland ES, Johnsen G, Eikrem W, Throndsen J, LiaaenJensen S (1995) Pigments of Bathycoccus prasinos (Prasinophyceae): methodological and chemostatic implications. J Phycol 31:554-561

Falk-Pettersen IB, Lønning S (1983) Reproductive cycles of two closely related sea urchin species, Strongylocentrotus droebachiensis (O.F. Müller) and Strongylocentrotus pallidus (G.O. Sars). Sarsia 68:157-164

Gonor JJ (1972) Gonad growth in the sea urchin, Strongylocentrotus purpuratus (Stimpson) (Echinodermata: Echinoidea) and the assumptions of gonad index methods. J Exp Mar Biol Ecol 10:89-103

Griffiths M, Perrott P (1976) Seasonal changes in the carotenoids of the sea urchin Strongylocentrotus droebachiensis. Comp Biochem Physiol 55B:435-441

Hagen NT (1996a) Echinoculture: from fishery enhancement to closed cycle cultivation. World Aquacult 27(4):6-19

Hagen NT (1996b) Tagging sea urchins: a new technique for individual identification. Aquaculture 139:271-284

Hagen NT (1998) Effect of food availability and body size on out-of-season gonad yield in the green sea urchin, Strongylocentrotus droebachiensis. J Shellfish Res 17: 1533-1539

Himmelman JH (1978) Reproductive cycle of the green sea urchin, Strongylocentrotus droebachiensis. Can J Zool 56: 1828-1836

Lamare MD, Hoffman J (2004) Natural variation of carotenoids in the eggs and gonads of the echinoid genus, Strongylocentrotus: implications for their role in ultraviolet radiation photoprotection. J Exp Mar Biol Ecol 312: 215-233

Lawrence JM (1975) On the relationships between marine 
plants and sea urchins. Oceanogr Mar Biol Annu Rev 13: 213-286

Lawrence JM, Montoya R, McBride SC, Harris LG (2004) Carotenoid concentrations and profiles in testes, ovaries and eggs of the sea urchins Strongylocentrotus droebachiensis, Strongylocentrotus franciscanus and Lytechinus variegatus. In: Lawrence JM, Guzmán O (eds) Sea urchins: fisheries and ecology. DEStech Publications, Lancaster, PA, p 173-178

Lawrence JM, Lawrence A, Watts SA (2007) Feeding, digestion and digestibility. In: Lawrence JM (ed) Edible sea urchins: biology and ecology, Vol 37. Elsevier, Amsterdam, p 135-158

Matsuno T, Tsushima M (2001) Carotenoids in sea urchins. In: Lawrence JM (ed) Edible sea urchins. Elsevier, Amsterdam, p 115-138

Meidel S, Scheibling RE (1998) Annual reproductive cycle of the green sea urchin, Strongylocentrotus droebachiensis, in differing habitats in Nova Scotia, Canada. Mar Biol 131: 461-478

Munk JE (1992) Reproduction and growth of green sea urchins Strongylocentrotus droebachiensis (Mueller) near Kodiak, Alaska. J Shellfish Res 11:245-254

Oganesyan SA (1998) Reproductive cycles of the echinoid Strongylocentrotus droebachiensis in the Barents Sea. In: Mooi R, Telford M (eds) Echinoderms: San Francisco. Balkema, Rotterdam, p 765-768

Pearce CM, Daggett TL, Robinson SMC (2003) Effects of

Editorial responsibility: Josep-Maria Gili,

Barcelona, Spain starch type, macroalgal meal source, and $\beta$-carotene on gonad yield and quality of the green sea urchin, Strongylocentrotus droebachiensis (Müller), fed prepared diets. J Shellfish Res 22:505-519

Pearce CM, Daggett TL, Robinson SMC (2004) Effect of urchin size and diet on gonad yield and quality in the green sea urchin (Strongylocentrotus droebachiensis). Aquaculture 233:337-367

> Plank LR, Lawrence JM, Lawrence AL, Olvera RM (2002) The effect of dietary carotenoids on gonad production in the sea urchin Lytechinus variegatus. J World Aquacult Soc 33:127-137

> Robinson SMC, Castell JD, Kennedy EJ (2002) Developing suitable colour in the gonads of cultured green sea urchins (Strongylocentrotus droebachiensis). Aquaculture 206: 289-303

Shpigel M, Schlosser SC, Ben-Amotz A, Lawrence AL, Lawrence JM (2006) Effects of dietary carotenoid on the gut and the gonad of the sea urchin Paracentrotus lividus. Aquaculture 261:1269-1280

Sokal RR, Rohlf FJ (1995) Biometry. The principles and practice of statistics in biological research. W. H. Freeman, San Francisco, CA

Tsushima M (2007) Carotenoids in sea urchins. In: Lawrence JM (ed) Edible sea urchins: biology and ecology, Vol 37. Elsevier, Amsterdam, p 159-166

Zar JH (1999) Biostatistical analysis. Prentice-Hall, Upper Saddle River, NJ

Submitted: December 4, 2007; Accepted: July 15, 2008

Proofs received from author(s): August 12, 2008 